Review

\title{
Function and Role of ATP-Binding Cassette Transporters as Receptors for 3D-Cry Toxins
}

\author{
Ryoichi Sato *, Satomi Adegawa, Xiaoyi Li, Shiho Tanaka and Haruka Endo \\ Graduate School of Bio-Applications and Systems Engineering, Tokyo University of Agriculture and Technology, \\ Naka 2-24-16, Koganei, Tokyo 184-8588, Japan; s174092v@st.go.tuat.ac.jp (S.A.); s159217x@st.go.tuat.ac.jp (X.L.); \\ shiho_9099@yahoo.co.jp (S.T.); haruka@edu.k.u-tokyo.ac.jp (H.E.) \\ * Correspondence: ryoichi@cc.tuat.ac.jp; Tel./Fax: +81-42-388-7277
}

Received: 25 January 2019; Accepted: 15 February 2019; Published: 19 February 2019

\begin{abstract}
When $\mathrm{ABC}$ transporter family $\mathrm{C} 2$ (ABCC2) and $\mathrm{ABC}$ transporter family $\mathrm{B} 1$ (ABCB1) were heterologously expressed in non-susceptible cultured cells, the cells swelled in response to Cry1A and Cry3 toxins, respectively. Consistent with the notion that 3D-Cry toxins form cation-permeable pores, Bombyx mori ABCC2 (BmABCC2) facilitated cation-permeable pore formation by Cry1A when expressed in Xenopus oocytes. Furthermore, BmABCC2 had a high binding affinity $\left(K_{D}\right)$ to Cry1 Aa of $3.1 \times 10^{-10} \mathrm{M}$. These findings suggest that $\mathrm{ABC}$ transporters, including $\mathrm{ABCC} 2$ and $\mathrm{ABCB} 1$, are functional receptors for 3D-Cry toxins. In addition, the Cry2 toxins most distant from Cry1A toxins on the phylogenetic tree used $\mathrm{ABC}$ transporter $\mathrm{A} 2$ as a receptor. These data suggest that $3 \mathrm{D}-\mathrm{Cry}$ toxins use $\mathrm{ABC}$ transporters as receptors. In terms of inducing cell swelling, $\mathrm{ABCC} 2$ has greater activity than cadherin-like receptor. The pore opening of $A B C$ transporters was hypothesized to be linked to their receptor function, but this was repudiated by experiments using mutants deficient in export activity. The synergistic relationship between ABCC2 and cadherin-like receptor explains their ability to cause resistance in one species of insect.
\end{abstract}

Keywords: mode of action; 3-domain Cry toxin; functional receptor; $\mathrm{ABC}$ transporter; $\mathrm{ABCC2}$; cadherin-like receptor

Key Contribution: $A B C$ transporters are one of the primary receptors for several 3D-Cry toxins and synergism of $A B C$ transporters and cadherin-like receptor seems to play a major role in susceptibility determination for 3D-Cry toxins of insects. Appreciation of these is important for developing strategies to prevent resistance development for 3D-Cry toxins of insects.

\section{Introduction}

Bacillus thuringiensis is the most widely used bio-pesticide, and it makes several insecticidal proteins including Cry toxins. The largest group of Cry toxins is called 3-domain Cry (3D-Cry) toxin, since its activated form consists of three domains. 3D-Cry toxin genes are essential for the generation of genetically modified insect resistant crops. However, heavy use of 3D-Cry toxin spray formulations and the expansion of cultivation of genetically modified organism (GMO) foods has led to the emergence of insects resistant to 3D-Cry toxins. Determining the causative agent of this resistance is important for developing strategies to prevent resistance development and for understanding the mode of action of 3D-Cry toxins [1,2]. Mapping the locus of the causative gene of a highly resistant tobacco budworm, Heliothis virescens, identified ATP-binding cassette (ABC) transporter family C2 (ABCC2) [3]. $\mathrm{ABCC} 2$ was also found to be responsible for the Cry1Ac toxin resistance of the diamondback moth, Plutella xylostella $[4,5]$. In Japan, the resistance of several strains of silkworm, Bombyx mori, to Cry1 Ab was due to insertion of one amino acid residue in ABCC2 [6]. Resistance is thought to be linked to 
deficiency in factors related to the mode of action of 3D-Cry toxins in the insect midgut. ABCC2 is a membrane-spanning protein consisting of two transmembrane domains (TMD1 and TMD2) and two nucleotide-binding domains (NBD1 and NBD2). The binding affinity of 3D-Cry toxins to brush-border membrane vesicles from resistant strains was lower than that of susceptible strains $[7,8]$. Therefore, $\mathrm{ABCC} 2$ was considered a functional receptor for 3D-Cry toxins, although direct evidence was lacking.

Cadherin-like receptor is also linked to resistance to 3D-Cry toxins [9-12], albeit a little lower level of resistance than $\mathrm{ABCC} 2[3,5,13]$. The reason for the difference in the levels of resistance was unknown. Why deficiency in each receptor confers resistance in the same insect species was also unclear. For example, YHD2, a Cry1Ac-resistant strain of $H$. virescens, harbors several major resistance genes (such as BtR-4 and BtR-6) [10]. It is axiomatic that only deficiency in the most important determinant of susceptibility induces resistance. Typically, deficiency in a less important factor is overridden by the presence of the most important determinant. Therefore, why deficiency in a second receptor also induces resistance in the same species of insect has been unclear.

A Helicoverpa armigera strain with 6000-fold increased resistance to Cry2Ab [14] had a mutation in $\mathrm{ABC}$ transporter family $\mathrm{A} 2$ ( $A B C A 2)$, suggesting that $\mathrm{ABCA} 2$ is linked to Cry2Ab resistance [15]. This was confirmed by generating knockout insects using clustered regularly interspaced short palindromic repeats (CRISPR)/Cas9 genome editing [16]. ABCB1 was found to be linked to 6400-fold increased resistance to Cry3Aa in the leaf beetle, Chrysomela tremula, and ABCB1 was identified as a functional receptor for Cry3Aa by heterologous expression in Spodoptera frugiperda (Sf9) cells [17]. Cry1 and Cry2 toxins are located on the most distant sides of the 3D-Cry toxin phylogenetic tree, and Cry3 in the middle (Figure 1). Thus, 3D-Cry toxins might have evolved through adaptation from one family to the other families of $A B C$ transporters. $A B C$ transporters export waste substances from cells opening the gate of their latent pore [18]. In addition, 3D-Cry toxin was indicated to insert helices into the cell membrane to make pore [19-22]. Thus, the working hypothesis was that 3D-Cry toxins insert helices into the opening gate of the pore [23]. Actually, B. mori ABCC2 (BmABCC2) exports the fluorescent $\mathrm{Ca}^{2+}$ indicator, $\mathrm{X}$-Rhod-1, from Sf9 cells [24]. However, it is unlikely that all 3D-Cry toxins use only ABC transporters as receptors; indeed, Cry1 toxins can also use cadherin-like receptor $[9,12]$, which lacks an intramolecular pore. Therefore, we were curious about the link between opening of the intramolecular pore and the receptor function of $\mathrm{ABC}$ transporters.

Several reviews of the mode of action of 3D-Cry toxins have been published; however, most focused on the role of cadherin-like receptor, aminopeptidase $\mathrm{N}$, and alkaline phosphatase in pore formation [25]. As discussed above, high level resistance is linked to deficiency in $A B C$ transporters, which generated further questions on the mode of action of 3D-Cry toxins.

Here, we review biochemical, cell biological, and physical studies of the role of ABC transporters as receptors for 3D-Cry toxins.

\section{ABC Transporters are One of the Primary Receptors for Several 3D-Cry Toxins}

\subsection{ABC Transporters Facilitate Induction of Cell Swelling by 3D-Cry Toxins}

3D-Cry toxins cause insect death by inducing cell swelling in the midgut [26]. Incubation of B. mori midgut with $100 \mathrm{nM}$ Cry1Aa resulted in swelling of columnar cells, followed by their protrusion from the epithelium and rupture within $60 \mathrm{~min}$. Thus, if ABC transporters are receptors for 3D-Cry toxins, they should induce swelling in non-susceptible cultured cells in the presence of 3D-Cry toxins. At concentrations insufficient to induce cell swelling, 3D-Cry toxins induced apoptosis of columnar cells in B. mori, as indicated by nuclear fragmentation, within 2 to 3 days [27]. This programmed cell death promoted repair of damaged midgut tissue by removing injured cells. Furthermore, oncosis-like programmed cell death occurred in S5 cells heterologously expressing cadherin-like receptor [28,29]. However, this oncosis-like programmed cell death pathway has not been reported to induce cell swelling and collapse of the midgut. 
BmABCC2 facilitated induction of swelling by Cry1Aa, Cry1Ab, and Cry1Ac in non-susceptible Sf9 cells when heterologously expressed using a baculovirus expression system [30]. The cells started swelling within $3 \mathrm{~min}$, became non-refractive, reached the maximum volume after $15 \mathrm{~min}$, and burst when they were administrated with $1.2 \mu \mathrm{M}$ Cry1Aa toxin. As more than $90 \%$ of the cells expressed BmABCC2, a quantitative evaluation was conducted [30] (Video S1). BmABCC2 also facilitated induction of swelling by Cry1As in human HEK293T cells [31]. Sf9 and HEK293T cells are phylogenetically dissimilar and do not have any adaptor molecules for BmABCC2. Therefore, it is not easy to imagine that BmABCC2 triggered the same kind of programed cell death in these two cell lines, although cadherin-like receptor triggered programed cell death and facilitated induction of swelling simultaneously in S5 cells [28,29]. When BmABCC2 was expressed in wing-disc cells of Drosophila melanogaster using the Gal4-UAS system, the cells became susceptible, swelled, and died in response to administration of $200 \mathrm{nM}$ Cry1Aa in vitro [32]. In addition, when transgenic D. melanogaster larvae were injected with $25 \mathrm{nM}$ Cry1 Aa, the wing disc died by necrosis (with cell swelling) and wingless adults emerged [32]. ABCC2s from other insect species also facilitate cell-swelling induction by Cry1A. H. virescens ABCC2 (HevABCC2) conferred susceptibility to Sf9 cells [33]. Drosophila melanogaster larvae expressing PxABCC2 in the midgut showed susceptibility and died upon feeding on a diet containing 0.05 ppm Cry1Ac [34]. As described above, the susceptibility-conferring ability of ABCB1 from C. tremula was confirmed using a heterologous expression system in Sf9 cells [17]. Therefore, heterologous expression of $\mathrm{ABC}$ transporters facilitates Cry1As-mediated induction of cell swelling. Cell swelling shown in these reports coincides well the symptom seen in the Cry1As intoxicated insect midgut [26].

\subsection{BmABCC2 Facilitates Cation-Permeable Pore Formation by Cry1A Toxins}

In artificial phospholipid membrane vesicles or planar lipid bilayers reconstituted with purified aminopeptidase $\mathrm{N}$ or GPI-linked receptor complex, Cry1A formed cation-permeable pores and transports $\mathrm{Rb}^{+}$through the membrane [20-22]. An osmotic swelling assay showed that the internal diameter of the pore formed by Cry1Ac was approximately $2.4 \mathrm{~nm}$ [35]. In addition, apical-to-basal $\mathrm{K}^{+}$ flux was detected by short-circuit current measurement in the midgut of an insect treated with Cry1 Aa and Ac [36]. Thus, Cry1A forms cations-permeable pores in lipid membranes.

According to the Structural Classification of Proteins [37] (http:/ / scop.mrc-lmb.cam.ac.uk/scop/), domain I of 3D-Cry toxins is the membrane translocation domain. The $\alpha$-helices of this domain in colicin A and diphtheria toxin form pores or translocate to the cell membrane [38,39]. Furthermore, cell swelling is induced by water influx into the cytosol through the cell membrane [40], likely driven by the osmotic pressure generated by $\mathrm{K}^{+}$influx [41]. Therefore, the facilitation of cation-permeable pore formation by ABCC2 suggests it is a functional receptor for 3D-Cry toxins.

To determine whether it facilitates cation-permeable pore formation by 3D-Cry toxins, BmABCC2 was heterologously expressed in the Xenopus oocyte membrane and subjected to two-electrode voltage clamp assay. BmABCC2 facilitated the inward negative current (inward flow of cations) generated by Cry1 Aa and Cry1 $\mathrm{Ab}$ [42]. In addition, the magnitude of the inward negative current increased continuously; a similar result was obtained using the combination of BmABCC 2 and Cry $1 \mathrm{Ab}$. Thus, it is likely that one molecule of $\mathrm{BmABCC} 2$ can continuously facilitate pore formation by $\mathrm{Cry} 1 \mathrm{~A}$ toxins, i.e., the cycle of Cry1A associating with BmABCC2, inserting $\alpha$-helices into the membrane, and dissociating from $B m A B C C 2$ repeats continuously. Furthermore, after incubation with a high concentration of Cry1A, the pigment at the animal pole of $B m A B C C 2$-expressing Xenopus oocytes was dispersed and the cell membrane ruptured within $1 \mathrm{~h}$ [42]. The same principle may be in operation in the midgut columnar cells of insects exposed to Cry1A.

\subsection{Binding to 3D-Cry Toxins}

Receptors must be able to bind their target molecules. Thus, receptors in the midgut cell membrane were identified by screening for molecules that bind to 3D-Cry toxins using ligand 
blotting and pull-down assays. This resulted in the identification of cadherin-like receptor [43], aminopeptidase N [44], alkaline phosphatase [45], chlorophyllide-binding protein P252 [46,47], and BTR-270 glycoprotein [48] as candidate functional receptors. However, there was no report on the identification of $\mathrm{ABCC} 2$.

In a ligand blotting assay conducted in the authors' laboratory, $10 \mathrm{ng}$ BmABCC2 separated by sodium dodecyl sulfate polyacrylamide gel electrophoresis (SDS-PAGE) did not bind to Cry1Aa toxin, likely because of denaturation of its 12 membrane-spanning domains. Thus, the binding ability of ABCC2 might be lost upon disruption of its three-dimensional structure. To evaluate the binding ability of ABCC2, BmABCC2 was produced as a FLAG-tagged protein in Sf9 cells using a baculovirus expression system, solubilized with n-dodecyl- $\beta$-D-maltoside (used for X-ray crystallography of $A B C$ transporters [49]), purified using an anti-FLAG ${ }^{\circledR} \mathrm{M} 2$ affinity gel, and its binding ability was assessed by dot blotting and surface plasmon resonance (SPR) [50]. SPR showed that BmABCC2 had a very low dissociation rate and a dissociation constant $\left(K_{D}\right)$ of $3.1 \times 10^{-10} \mathrm{M}$, indicating a high binding affinity for Cry1Aa [50].

The high binding affinity and promotion of cell-swelling induction and cations-permeable pore formation of Cry1A indicate that BmABCC2 is a functional receptor for Cry1A.

\section{Role of $A B C$ Transporters as Receptors for 3D-Cry Toxins}

By gene silencing in larvae of Spodoptera exigua and P. xylostella, SeABCC3 and PxABCC3 were found to function as receptors for Cry1Ac [51,52]. In addition, heterologous expression of SeABCC3 conferred susceptibility to $100 \mathrm{nM}$ Cry1Aa and $1 \mu \mathrm{M}$ Cry8Ca in HEK293T cells [31]. Similarly, Spodoptera litura ABCC3 (SlABCC3) expression conferred susceptibility to $20 \mathrm{nM}$ Cry1Ac in High Five cells [53]. Furthermore, BmABCC 3 was linked to the induction of cell swelling by $100 \mathrm{nM}$ Cry1Aa in HEK293T cells [54]. These suggests that ABCC3 also function as a receptor in lepidopteran insects.

$A B C C 3$ is most phylogenetically similar to $A B C C 2$, and $A B C C 2$ and $A B C C 3$ looks to make lepidopteran-specific clade in a larger clade which include human ABCC4 (humABCC4) (humABCC4 clade, tentatively) [31,55] (Figure 1). This explains the specificity of Cry1A for lepidopteran insects [31]. In contrast, although Cry1Ca and Cry1Da are active in the larvae of B. mori and S. exigua, BmABCC2, BmABCC3, SeABCC2, and SeABCC3 did not function as receptors for these toxins in Sf9 or HEK293T cells [31,54] (Figure 1). Thus, Cry1Ca and Cry1Da looks not to target ABCC2 and ABCC3 at least in B. mori or S. exigua. Members of humABCC4 clade, $\mathrm{ABCC} 1, \mathrm{ABCC} 4, \mathrm{ABCC} 5, \mathrm{ABCC} 6$, $\mathrm{ABCC} 7$, and $\mathrm{ABCC} 8$ are close to $\mathrm{ABCC} 2$ and $\mathrm{ABCC} 3$ [55]. They could be candidate functional receptors for 3D-Cry toxins close to Cry1A (e.g., Cry1B, Cry1C, and Cry1D) (Figure 1). In contrast, Tribolium castaneum $\mathrm{ABCC} 4$ (TcABCC4), BmABCC2, and SeABCC3 functioned as receptors for Cry8Ca in HEK293T cells [31]. The clade formed by Cry8 and Cry9 is adjacent to the clade formed by Cry1 and Cry7 (Figure 1). TcABCC4 is assigned to the humABCC4 clade and is separated from BmABCC2/SeABCC 3 by several factors [31,55] (Figure 1). Furthermore, several humABCC4-clade molecules (e.g., BmABCC4 and BmABCC6) are highly expressed in B. mori midgut cells [55]. Therefore, functional receptors for Cry7 and Cry9 that are active to $B$. mori are also likely present in the humABCC4 clade.

A laboratory-selected strain of the oligophagous leaf beetle $C$. tremula showed 6400 -fold increased resistance to Cry3Aa in comparison to a susceptible strain; the increased resistance was related to one recessive allele [56]. A linkage analysis showed that deficiency in ABC transporter B1 (CtABCB1) mediated the increased resistance. Furthermore, in Sf9 cells, CtABCB1 functions as a receptor for Cry3Aa [17]. These data suggest that ABCB1 is the most important receptor for Cry3Aa.

Linkage mapping showed that resistance to Cry2Ab in Helicoverpa armigera and Helicoverpa punctigera was related to loss-of-function mutations of $\mathrm{ABC}$ transporter $\mathrm{A} 2$ ( $A B C A 2)$ genes [15]. In addition, $H a A B C A 2-$ knockout strains of $H$. armigera showed high-level resistance to Cry2Aa and $\mathrm{Cry} 2 \mathrm{Ab}$ [16]. Knockout of $\mathrm{BmABCA} 2$ resulted in high-level resistance to Cry2Aa and Cry2Ab (Watanabe, personal communication). In addition, in our experiment, BmABCA2 facilitated induction 
of swelling by Cry2Aa and Cry2Ab in HEK293T cells (in preparation). Thus, ABCA2 must be considered to be the major functional receptor for Cry2Aa and Cry2Ab in these insects.

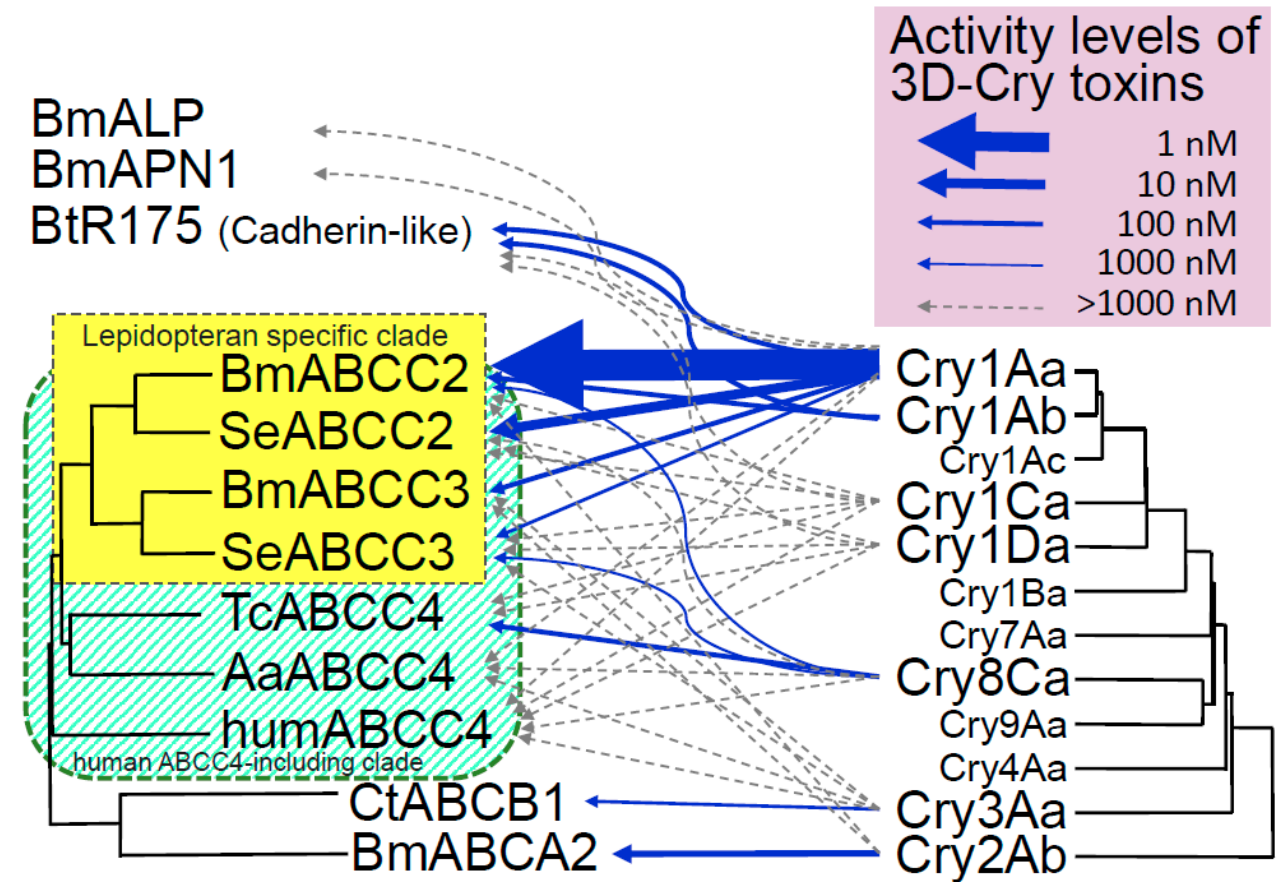

Figure 1. Use of $A B C$ transporters as functional receptors by 3D-Cry toxins. Receptor activity data for Cry2Ab using ABC transporter-expressing HEK293T cells or Sf9 cells and previous results for Cry toxins [17,30,31,54]; arrow width indicates the level of activity. Phylogenetic tree of ABC transporters generated using the amino acid sequences of BmABCC2 (BAK82127.1), SeABCC2 (AIB06821.1), BmABCC3 (XP_012547933.1), SeABCC3 (AIB06823.1), TcABCC4 (XP_969849.1), AaABCC4 (APG42670.1), humABCC4 (NP_005836.2), CtABCB1 (APK18402.1), and BmABCA2 (ALE60402.1) with CLUSTAL W. Bm, Bombyx mori; Ct, Chrysomela tremula; Se, Spodoptera exigua; Tc, Tribolium castaneum; Aa, Aedes albopictus. A part of the phylogenetic tree of Cry toxins (Bacillus thuringiensis Toxin Nomenclature; http:/ /www.lifesci.sussex.ac.uk/home/Neil_Crickmore/Bt/intro.html).

Cry1 and Cry2 are located at the most distant sides of the 3D-Cry toxin phylogenetic tree (Figure 1), whereas $\mathrm{Cry} 3$ is located in the middle. Therefore, 3D-Cry toxins may have adapted to use $A B C A, A B C B$, and $A B C C$ during evolution. $A B C B$ is closest to $A B C C$ and $A B C A$ is most distant from $A B C C$ [57], and $A B C D, A B C E, A B C F, A B C G$, and $A B C H$ are between $A B C A$ and $A B C C$. Therefore, it is no wonder that functional receptors of the other 3D-Cry toxins will be found from these $\mathrm{ABC}$ transporters.

\section{Receptor Functions of ABCC2, Cadherin-Like Receptor, and Aminopeptidase N}

ABCC2 deficiency sometimes causes higher-level resistance than does deficiency in cadherin-like receptors $[3,5,13]$. To determine why, the receptor function of these two factors was investigated in non-susceptible cultured cells.

Sf9 cells expressing the toxin-binding region of BtR175, BtR175-TBR began to respond to Cry1Aa, $\mathrm{Ab}$, and $\mathrm{Ac}$ at 100, 100, and $400 \mathrm{nM}$, respectively [30]. In contrast, BmABCC2-expressing Sf9 cells began to respond to Cry1 Aa, $\mathrm{Ab}$, and $\mathrm{Ac}$ at $100 \mathrm{pM}, 10 \mathrm{nM}$, and $1 \mathrm{nM}$, respectively [30,50]. Thus, the susceptibility of BmABCC2-expressing cells is 1,000-, 10-, and 400-fold higher than that of cells expressing BtR175-TBR. In the other experiment, Sf9 cells expressing BtR175 were susceptible to $130 \mathrm{nM}$ Cry1Aa [9]. Furthermore, HEK293T cells expressing BtR175-TBR variants were susceptible to $100 \mathrm{nM}$ Cry1Aa [58]. In contrast, HEK293T cells expressing BmABCC2 began to respond (cell swelling) at $1 \mathrm{nM}$ [54]. Heliothis virescens ABCC2 (HevABCC2) conferred high susceptibility to rupture by Cy1A on Sf9 cells [33]; however, the cadherin-like receptor of H. virescens, HevCaLP, conferred low susceptibility. 
In a D. melanogaster wing-disc expression system using Gal4-UAS, BmABCC2, but not BtR175-TBR, conferred susceptibility to $100 \mathrm{nM}$ Cry1Aa [32]. BtR175 and BtR175-TBR have similar abilities to facilitate induction of cell swelling by 3D-Cry toxins [9,30]. Thus, ABCC2 looked to confer greater susceptibility to Cry1A than did cadherin-like receptor, irrespective of the heterologous expression system used. However, there is only the meager evidence of Western blotting for the equivalence of expression levels of $\mathrm{ABCC} 2$ and cadherin-like receptor. The cell swelling induction-facilitating activity of BmABCC2 and BtR175 cannot be compared based on the same number of expressing molecules. Therefore, it is difficult to say that differences in the receptor activity of these molecules are really due to the differences in the receptor function.

The amount of complementary RNA (cRNA) of BmABCC2 and BtR175-BTR injected into the Xenopus oocyte expression system was adjusted to $500 \mathrm{ng}$ [42]. In BmABCC2-expressing oocytes, the inward negative current increased within $100 \mathrm{~s}$ in the presence of $0.625 \mathrm{nM}$ Cry1Aa [42], and $10 \mathrm{nM}$ $\mathrm{Cry} 1 \mathrm{Ab}$ also increased the inward negative current. However, in BtR175-TBR-expressing oocytes, no inward negative current was observed within $100 \mathrm{~s}$, irrespective of the Cry1Aa concentration. Indeed, an inward negative current was detected only after $60 \mathrm{~min}$. BmABCC2 looked to have 5,000-fold higher current induction-facilitating activity than BtR175-TBR when factors of time and Cry1Aa concentration was multiplied [42]. This suggests that BmABCC2 has greater Cry1A-receptor activity than does BtR175. This may explain why ABCC2 deficiency leads to greater resistance than does cadherin-like receptor deficiency.

Aminopeptidase $\mathrm{N}$ has been reported as an important functional receptor for 3D-Cry toxins, but its function is unclear. In an in vitro cell-burst assay using collagenase-dissociated $B$. mori midgut epithelial cells, anti-BtR175, but not anti-APN1 antiserum inhibited Cry1As [59]. Tanaka et al. investigated the receptor activity of B. mori APN1 (BmAPN1) using Baculovirus-Sf9 heterologous expression system and cRNA-injected Xenopus oocyte expression system [30,42]. Expression of BmAPN1 alone did not facilitate induction of cell swelling by Cry1Aa or a negative inward current. In addition, in the other reports, heterologously expressed APNs did not show receptor activity [60-62]. Although APN was reported in several other papers to facilitate toxin-induced cell swelling, the cells used in those papers appeared to have a problematic condition. Modification of APN by incomplete sugar chains may explain its lack of receptor activity in heterologous expression systems [63]. However, because M. sexta APN conferred susceptibility to Cry1Ac on D. melanogaster [64], it is unclear why Sf9 cells, lepidopteran insect cells cannot modify APN with sugar chains. Furthermore, Cry1Aa can bind to non-sugar-modified APN [65]. However, Cry1Aa did not use BmAPN1 as a functional receptor in heterologous expression systems [30,42]. Also, Cry1 Ac formed $\mathrm{K}^{+}$channels in artificial lipid membranes reconstituted with partially purified APN from $M$. sexta [20]. Cry1A promotes $\mathrm{Rb}+$ release from phosphatidylcholine vesicles reconstituted with partially purified APNs from $H$. virescens and M. sexta [21,22]. However, APNs were contaminated with some proteins of 250-300 kDa, which is in the range of mass of putative ABCC2 dimer and P252 [24,46]. Thus, whether the electric current in, and $\mathrm{Rb}^{+}$release from, the artificial membrane were dependent on APN is unclear. In addition, whether pore formation by 3D-Cry toxins detected in these experiments really means adequate activity in the induction of swelling and rupture of the real midgut columnar cells is unclear. APN reportedly facilitates pore formation after receiving oligomerized 3D-Cry toxins from cadherin-like receptor $[25,66,67]$. This may explain why APN did not facilitate induction of cell swelling when solely expressed in cultured cells. However, this contradicts the aforementioned hypothesis derived from the results of experiments using partially purified APN-containing artificial membranes [20-22], which lacked cadherin-like receptor.

No linkage-mapping study has shown that APN induces high-level resistance to 3D-Cry toxins, and thus the role of APN in the mode of action of 3D-Cry toxins remains obscure. This is reasonable if APN deficiency is lethal to the insect. In contrast, the susceptibility of insect larvae was reduced by downregulation of APN by RNA interference [68,69]. However, further work is required to confirm this, as the downregulation APN was inadequate and the decrease in susceptibility was obscure. Generating 
knockout insects by genome editing may help to clarify the role of APN as a receptor. Recently, APN was hypothesized to collect 3D-Cry protoxins and pass them to cadherin-like receptor [70].

\section{Relationship between Binding Affinity to 3D-Cry Toxins and Receptor Activity}

The specificity and activity of 3D-Cry toxins should be determined by their receptor-binding affinity. The receptor activities of BmABCC2, BmABCC3, and BtR175 were evaluated using several heterologous expression systems, and their binding affinities to 3D-Cry toxins were determined by SPR [31,50,54]. The relationships between the 3D-Cry toxin-binding affinities and receptor activities of BmABCC2, BmABCC3, and BtR175 in cultured cells are shown in Table 1. In general, receptors with high toxin-binding affinities induced cell swelling in low concentration of 3D-Cry toxins. For example, only BmABCC2 and BmABCC2-R (BmABCC2 derived from a Cry1Ab resistant strain, Chinese No.2) with $K_{D}$ values $<10^{-10} \mathrm{M}$ responded to $0.1-10 \mathrm{nM}$ 3D-Cry toxin (Table 1). In contrast, receptors with $K_{D}$ values $>10^{-7} \mathrm{M}$ did not facilitate induction of cell swelling by $1 \mu \mathrm{M}$ Cry1Aa, Cry1Ab, Cry1Ca, Cry1Da, Cry3Bb, or Cry8Ca. For BmABCC3 and Cry1Aa, and TcABCC4A and Cry8Ca, a $K_{D}<10^{-8} \mathrm{M}$ indicated receptor activity. However, some molecules with $K_{D}$ of $10^{-8} \mathrm{M}$ did not function as receptors (Table 1). Furthermore, although the $K_{D}$ was $10^{-10} \mathrm{M}, \mathrm{BmABCC} 2$ showed low receptor activity for Cry1Ab (Table 1). This suggests that a factor other than binding affinity affects receptor function. The inability of BmABCC2-R, which was from a resistant B. mori strain, to function as a receptor for Cry1Ab despite a $K_{D}$ of $2.39 \times 10^{-8}$ was considered to be due to inhibition of some processes after binding by insertion of a tyrosine at position 234 of BmABCC2 [30].

Table 1. Partial correlation between binding affinity and cell swelling activity of Cry toxins.

\begin{tabular}{|c|c|c|c|}
\hline Receptor. & Toxin & $K_{D}(\mathrm{M})^{1}$ & Effective Conc. (nM) in Cell Swelling Assay ${ }^{2}$ \\
\hline \multirow{6}{*}{$\mathrm{BmABCC} 2$} & Cry1Aa & $3.1 \times 10^{-10}$ & 0.1 \\
\hline & Cry1Ab & $2.6 \times 10^{-10}$ & 100 \\
\hline & Cry1Ca & $1.7 \times 10^{-7}$ & $>10,000$ \\
\hline & Cry1Da & $2.3 \times 10^{-6}$ & $>2000$ \\
\hline & Cry3Bb & $2.0 \times 10^{-5}$ & $>500$ \\
\hline & Cry8Ca & $1.9 \times 10^{-5}$ & 1000 \\
\hline \multirow{2}{*}{$\mathrm{BmABCC} 2$ from resistant line } & Cry1Aa & $2.8 \times 10^{-10}$ & 10 \\
\hline & Cry1Ab & $2.4 \times 10^{-8}$ & $>1000$ \\
\hline \multirow{5}{*}{ BmABCC3 } & Cry1Aa & $3.4 \times 10^{-8}$ & 100 \\
\hline & Cry1Ab & $6.9 \times 10^{-8}$ & $>4500$ \\
\hline & Cry1Ca & $3.9 \times 10^{-7}$ & $>1000$ \\
\hline & Cry1Da & $4.2 \times 10^{-4}$ & $>1000$ \\
\hline & Cry3Bb & $4.0 \times 10^{-8}$ & $>1000$ \\
\hline \multirow{5}{*}{ TcABCC4A } & Cry1Aa & not detectable & $>1000$ \\
\hline & Cry1Ca & not detectable & $>2500$ \\
\hline & Cry1Da & not detectable & $>2000$ \\
\hline & Cry3Bb & $1.8 \times 10^{-5}$ & $>1700$ \\
\hline & Cry8Ca & $4.0 \times 10^{-8}$ & 100 \\
\hline BtR175(BmCad) & Cry1Aa & $7.2 \times 10^{-10}$ & 200 \\
\hline
\end{tabular}

${ }^{1}$ The values of $K_{D}$ were sited from reports of Adegawa et al. [50] and Endo et al. [31,54]. ${ }^{2}$ Lowest concentrations of toxins by which swollen cells were obviously induced were sited from reports of Tanaka et al. [30,71] Adegawa et al. [50] and Endo et al. [31,54].

In contrast, although the $K_{D}$ for BtR175-TBR and Cry1Aa is $7.2 \times 10^{-10} \mathrm{M}$ [50], Sf9 cells expressing BtR175-TBR facilitated induction of cell swelling by >200 nM Cry1Aa [30] (Table 1). The molecular shape, distance between the membrane and the 3D-Cry toxin-binding site, and the angle of binding of 
3D-Cry toxins might differ between BmABCC2 and BtR175-TBR. In addition, cadherin-like receptor induces oligomerization of 3D-Cry toxins $[66,70]$. Thus, to understand the reason of difference in the receptor activities of BmABCC2 and BtR175-TBR further studies are needed.

\section{Structures of BmABCC2 Responsible for Its Function as a Cry1Aa Toxin Receptor}

It is hypothesized that 3D-Cry toxins insert helices into the intramolecular pore of $\mathrm{ABC}$ transporters; indeed, this may explain the 1000-fold greater Cry1Aa-receptor activity of BmABCC2 than BtR175-TBR. Alternatively, the kinetic energy generated by opening the ABC transporter gate might trigger insertion of 3D-Cry toxins into the membrane. As receptors, Cry1A uses $A B C C 2$ and ABCC3; Cry8Ca uses ABCC2, ABCC3, and ABCC4; Cry2A uses ABCA2; and Cry3Aa uses ABCB1 (Figure 1). Therefore, 3D-Cry toxins appear to have adapted to use different $A B C$ transporters. The association of two nucleotide-binding domains using ATP molecules opens the intramolecular pore [18]. Quite unexpectedly, the receptor activity of two nucleotide-binding domain-deleted mutants of BmABCC2, D1del and D2del (Figure 2A), in the baculovirus-Sf9 heterologous expression system was similar to that of the wild type [24]. Thus, $A B C$ transporters seem to have another reasons for playing the roles of a high functional receptor.
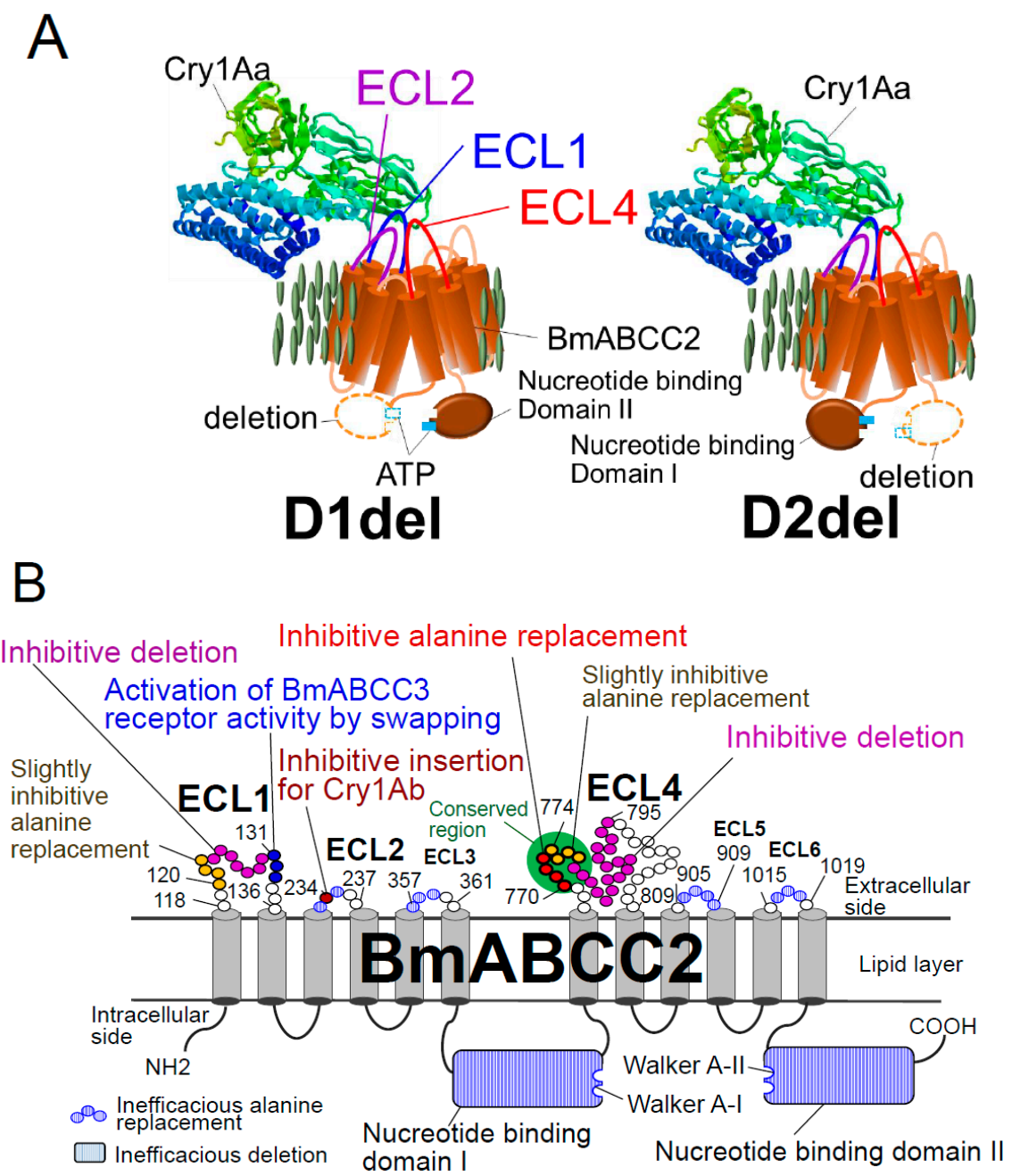

Figure 2. BmABCC2 structures that affect Cry1As receptor activity. (A) Nucleotide-binding domain-deleted BmABCC2 mutants, D1del and D2del, that exhibit receptor activity for Cry1Aa when expressed in the membranes of Sf9 or HEK293T cells [24]. ECL, extracellular loop. (B) Mutation sites in BmABCC2 that affect receptor activity for Cry1Aa or Cry1Ab [24] and a site at which amino acid replacement increases $\mathrm{BmABCC} 3$ receptor activity [54]. 
The extracellular loop (ECL) 1 and 4 domains of BmABCC2 were found to be related to its Cry1Aa receptor activity in deletion mutants generated using a baculovirus-Sf9 heterologous expression system (Figure 2), and the importance of ECL4 was confirmed using alanine-replacement mutants [24]. Recently, we further confirmed the importance of ECL1 using alanine-replacement mutants (in preparation). However, alanine replacement in ECL2, ECL3, ECL5, and ECL6 did not affect the receptor activity of BmABCC2 [24,54]. Thus, ECL1 and ECL4, the longest loops in BmABCC2, look important for its interaction with Cry1Aa (Figure 2).

In the High Five cell heterologous expression system, exchange of each ECL1-2 region between S. litura and S. frugiperda ABCC2 was indicated to be important to the specificity differences of Cry1AC toxin [72], as was the amino acid at position 125 in ECL1. Also, $\mathrm{Q}^{125}$ of H. armigera ABCC2 was a key determinant of receptor activity [72].

The resistant B. mori race Chinese No. 2, which has an additional tyrosine residue at position 234 in ECL2 of BmABCC2 (Figure 2B), had 3000-fold lower susceptibility to Cry1Ab than the susceptible race Ringetsu [6]. Indeed, additive insertion of alanine, phenylalanine, arginine, tryptophan, and histidine at this site reduced the receptor activity of BmABCC2 from Ringetsu in a baculovirus-Sf9 heterologous expression system [71] (Figure 2B). In contrast, all of these BmABCC2 mutants retained a high level of receptor activity for Cry1Aa. Thus, ECL2 appears not to be important for direct binding to Cry1A, but may be related to specificity. In incompatible combinations (e.g., BmABCC2-R of Chinese No. 2 and Cry1 $\mathrm{Ab}$ ), ECL2 may hamper binding to, or the membrane insertion of, the Cry1 Ab toxin [71].

$A B C C 2$ and $A B C C 3$ are closest in humABCC4 clade, but BmABCC2 conferred 1000-fold greater susceptibility to Cry1Aa on Sf9 cells than did BmABCC3 [30], and the $K_{D}$ of BmABCC2 for Cry1Aa was 100-fold lower than that of BmABCC3 [54] (Table 1). That is, the susceptibility-conferring activity of $A B C C 2$ and $A B C C 3$ is dependent on their binding affinity for Cry1Aa toxin. Several three serial amino acid residues (triplets) were swapped between BmABCC2 and BmABCC3, and two triplets from BmABCC2 ECL1 and ECL3, ${ }^{129} \mathrm{EAT}^{131}$ and ${ }^{363} \mathrm{YIS}^{365}$, respectively, increased the receptor activity of BmABCC3 [54] (Figure 2B). The ${ }^{129} \mathrm{EAT}^{131}$ replacement reduced the $K_{D}$ (increased affinity) of BmABCC3 six-fold, indicating that ECL1 is an important determinant of the receptor activity of BmABCC2 and BmABCC 3 . In contrast, ${ }^{363} \mathrm{YIS}^{365}$ replacement did not increase the binding affinity, suggesting that the increase in activity is caused by removal of structures that inhibit binding to 3D-Cry toxins or that hamper insertion of 3D-Cry toxins [54].

Comparisons of ABCC2 molecules from different insect species and of ABCC2 and ABCC3 from the same insect species have indicated the importance of ECL1 and ECL4 in determining receptor activity to Cry1A. ECL2 and ECL3 may also play roles in determining incompatibility. Therefore, ECL1, 2,3 , and 4 of $A B C C 2$ and $A B C C 3$ are determinants of the receptor activity and/or species specificity of Cry1A.

\section{ABCC2-Binding Sites in Cry1Aa}

The binding sites in Cry1Aa were analyzed by SPR using deletion mutants [50]. A loop-3 deletion mutant exhibited 1000-fold lower activity for facilitating induction of cell swelling in BmABCC2-expressing Sf9 cells and significantly lower toxin-binding affinity, suggesting that the BmABCC2-binding site is in loop 3. In contrast, a loop-2 deletion mutant had 1000-fold lower cell swelling induction-facilitating activity, but its toxin-binding affinity was unchanged. In addition, alanine replacement of three or four amino acids in the central region of loops 2 and 3 did not impact the binding affinity to $\mathrm{BmABCC} 2$, suggesting that the binding sites are located in the root of loops 2 and 3, which were not mutated. Mutants with unchanged binding affinity had long unchanged regions in the root of loops 2 and 3 [50]. The decreased binding affinity of the loop-3 deletion mutant may have been caused by structural distortion of the root region. In contrast, many mutants with a reduced ability to facilitate induction of cell swelling retained their Cry1Aa-binding affinity [50], suggesting that after binding to $\mathrm{BmABCC} 2$ the loops of Cry1 Aa have some other roles in its insertion into the membrane. 
The cadherin-like receptor-binding sites of Cry1A toxins are in the loop region of domain II [73-75]. A binding inhibition assay showed that the BmABCC2- and BtR175-TBR-binding sites overlap in the loop region [50]. Thus, the binding pocket of Cry1Aa domain II consists of loops that bind not only to the structurally related BmABCC2 and BmABCC3 [31] (Table 1) but also to the structurally unrelated BtR175. That is, the binding pocket has a multiple binding property. Moreover, multiple binding property was also reported for domain III of Cryla toxins [65]. Thus, Cry1A toxins has two multiple binding domains. This fact deeply impresses that $B$. thuringiensis is a pathogenic bacterium and uses toxins in hunting hosts. Although, several hypotheses have been proposed, the role of domain III in hunting is unclear. Only the loop region of domain II is adequately indicated to function as a binding site to functional receptors.

Binding of Cry1A to ABCC2 via ECL1 and ECL4 is unlikely to occur while the gate is open because ECL1 and ECL4 are separated [18]. In addition, binding of Cry1A to ABCC2 via the domain II loops would hamper insertion of the $\alpha$-helices of the domain I into the intramolecular pore of ABCC2, because these loops seemed to cover the closed gate of the latent pore (Figure 2A). Thus, the $\alpha$-helices likely access the lipid layer around ABCC2 molecules.

\section{Synergism of ABCCs and Cadherin-Like Receptor and Roles in Susceptibility Determination}

The receptor activity of BmABCC2 was 1000-5000-fold higher than that of BtR175-TBR [30,42], and so a deficiency in cadherin-like receptor should not cause resistance in principle. The susceptibility to Cry1Aa, Cry1Ab, and Cry1Ac of Sf9 cells expressing BtR175-TBR and BmABCC2 was 10-, 1000-, and 100-fold higher, respectively, than that of cells solely expressing BmABCC2 [30]. The significant increase in susceptibility caused by double expression was due to synergism between the two molecules [30]; indeed, HevCaLP and HevABCC2 also have synergistic activity [33]. Such synergism seems to be a major determinant of susceptibility to 3D-Cry toxins, because deficiency of cadherin-like receptor or ABCC2 induces resistance in the same insect species. Although the activity of a Cry1Ac mutant to cadherin-like receptor-knockout or ABCC2-knockout Trichoplusia ni strains decreased only slightly, it was decreased 3700-fold by knockout of both. Thus, the synergism of ABCC2 and cadherin is a determinant of the susceptibility of T. $n i$ larvae [76].

Formation of the cation-permeable pore in the cell membrane of Xenopus oocytes was accelerated eight-fold by co-expression of BtR175-TBR and BmABCC2 compared to expression of BmABCC2 only. Moreover, expression of BtR175-TBR alone did not lead to formation of cations-permeable pores. In contrast, the amount of membrane-bound oligomer was similar in BtR175-TBR- and BmABCC2-expressing oocytes [42]. Therefore, oligomers from BtR175-TBR-expressing oocytes should have remained on the membrane surface. In contrast, most oligomers from BmABCC2-expressing oocytes were considered to be inserted into the membrane. Because cadherin-like receptor has high 3D-Cry toxin oligomerization activity [25,67], the synergistic effect of BtR175-TBR and BmABCC2 is likely dependent on oligomer supply by BtR175 and promotion of pore formation by BmABC2. Plutella xylostella $\mathrm{ABCC} 2$ facilitates membrane insertion of Cry1Ac oligomers prepared by incubation with the M. sexta cadherin fragment CR7-CR12 [77]. It is uncertain whether 3D-Cry toxin is passed from cadherin-like receptor to $\mathrm{ABCC} 2$ as an oligomer or monomer, or whether $\mathrm{ABCC} 2$ facilitates membrane insertion of 3D-Cry toxin as a monomer or oligomer. Because the BmABCC2-binding site on Cry1Aa overlaps that of BtR175-TBR [50], BmABCC2 and BtR175-TBR should inhibit each other's binding to Cry1Aa. Therefore, a single Cry1Aa molecule is unlikely to be translocated from BtR175-TBR to $\mathrm{BmABCC} 2$. If this is the case, pore formation may involve aggregation of several Cry1Aa toxin monomer-holding BtR175-TBRs and monomer-holding BmABCC2s, followed by oligomerization of Cry1Aa and its membrane insertion with the assistance of BmABCC2. The putative roles of $\mathrm{ABCC} 2, \mathrm{ABCC} 3$, and cadherin-like receptor (based on the roles of BmABCC2, BmABCC3, and BtR175 in B. mori larvae) are shown in Figure 3. A signal transduction domain-deleted BtR175 mutant, BtR175-DEL, had the same ability to facilitate the induction of cell swelling as BtR175-TBR. In addition, the combination of BtR175-DEL and BmABCC2 exerted a synergistic effect in inducing cell swelling, 
similar to the combination of BtR175-TBR and BmABCC2 [78]. Therefore, oncosis-like programmed cell death induced by the signal-transduction domain of cadherin-like receptor is not relevant to the facilitation of induction of cell swelling by BtR175-TBR or the synergistic effect of BmABCC2 plus BtR175-TBR or that of BmABCC3 plus BtR175-TBR.

\section{Putative roles of $\mathrm{BmABCC} 2, \mathrm{BmABCC} 3$ and $\mathrm{BtR} 175$ in Cry1Aa toxin pore formation}

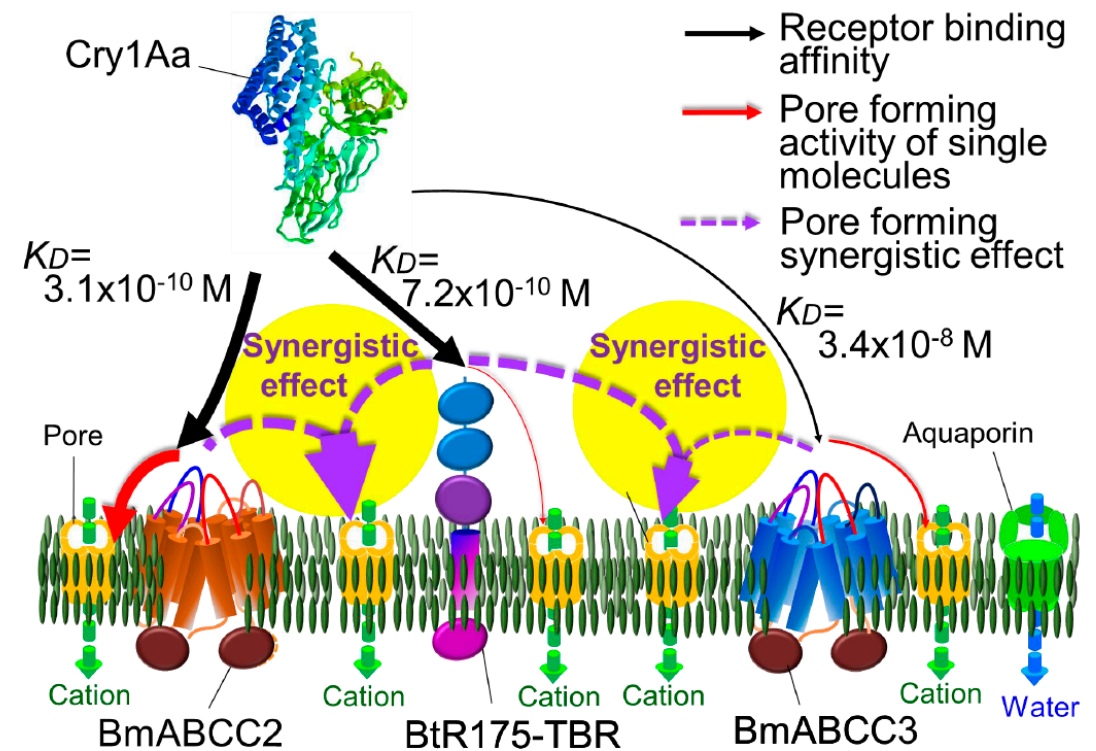

Figure 3. Putative roles of BmABCC2, BmABCC3, and BtR175 in Cry1Aa pore formation. Arrow thickness represents Cry1Aa receptor interaction and pore formation activities $[30,31,42,50]$.

A recombinant $M$. sexta cadherin essential toxin-binding region protein (CR12-MPED) enhanced the activity of Cry1Ac in M. sexta, H. virescens, and Heliothis zea larvae [79], in agreement with several prior reports $[51,80,81]$. This enhancement and synergistic effect may have the same underlying mechanism. In contrast, in the other reports, the toxin-binding region of cadherin did not increase the activity of Cry1 toxins [75,82]. In addition, in our experiment, recombinant BtR175-TBR did not enhance the activity of Cry1Aa in the BmABCC2 expressing Sf9 cells. Further studies of the relationship between enhancement of the activity by the toxin-binding region of cadherin and the synergistic effect of BtR175-TBR and BmABCC2 are thus warranted.

Cry1Aa, Cry1Ab, and Cry1Ac induced swelling of BmABCC2-expressing Sf9 cells at $100 \mathrm{pM}$, $10 \mathrm{nM}$, and $1 \mathrm{nM}$, respectively [30]. In contrast, the $\mathrm{LC}_{50}$ of Cry1Aa, Cry $1 \mathrm{Ab}$, and Cry1Ac in B. mori larvae was $0.45,0.26$, and $1.5 \mu \mathrm{g} / \mathrm{g}$, respectively [30]. Thus, the larvicidal activity of Cry1A toxins is not correlated with their induction of cell swelling in the BmABCC2-expressing Sf9 cells. This suggests that in B. mori larvae, several factors determine susceptibility to Cry1A toxins, including BtR175-TBR and BmABCC2. In addition, in our experiment, BtR175-TBR and BmABCC3 also exerted a synergistic effect in HEK293T cells. Thus, in B. mori larvae, not only BmABCC2 but also BmABCC3 may be involved in determining susceptibility to Cry1Aa through synergism with BtR175 (Figure 3). This is in agreement with the finding that knockout of BtR175, but not BmABCC2, induces resistance to Cry1Aa in B. mori larvae (Watanabe, personal communication). In contrast, mutation of BmABCC2 alone increased resistance to Cry1Ab 300-fold in $B$. mori larvae [6]. Also, susceptibility to Cry1Ab was rescued by introduction of $B m A B C C 2$ cDNA from a susceptible to a resistant $B$. mori strain [6]. Moreover, HEK293T cells expressing BmABCC3 were not susceptible to Cry1Ab [54]. Therefore, in B. mori larvae, BmABCC3 is unlikely to be a determinant of susceptibility to Cry1Ab. Similarly, ABCC3 seems not to be related to the susceptibility of insects, since 2800-fold increased resistance to 
Cry1Ac in P. xylostella and 1000-fold increased resistance to Cry1Ab and Cry1Ac in H. armigera $[5,13]$ were generated by $\mathrm{ABCC} 2$ deficiency alone. Thus, roles of $\mathrm{ABCC} 2, \mathrm{ABCC} 3$, and cadherin-like receptor (Figure 3) in the determining susceptibility seems to be different in each insect even to Cry1A toxins.

\section{Production of Multiple Toxins by B. Thuringiensis}

Several strains of B. thuringiensis produce multiple toxins, including 3D-Cry toxins, e.g., Cry1A, Cry1B, Cry1C, Cry1D and Cry2 [83,84]. A P. xylostella strain, NO-QA was resistant to Cry1A toxins but not to Cry1B, Cry1C, or Cry1D [85]. Conversely, P. xylostella BCS-Cry1C-2 was resistant to Cry1C but susceptible to Cry1A [86]. These suggests that several toxins use their original factors as receptors. Furthermore, an ABCA2 truncation-dependent Cry2Ab-resistant $H$. armigera strain was susceptible to Cry1Ac [15]. In addition, Cry1Aa, but not Cry1C or Cry1D, use ABCC2 and ABCC3 [54] (Figure 1). Therefore, simultaneous production of multiple 3D-Cry toxins that use different receptors promotes survival in B. thuringiensis by preventing development of host resistance. The B. thuringiensis subspecies israelensis (Bti) is used to control mosquitoes and black flies; however, no outbreak of highly resistant strains has been reported [87,88]. This might be due to production of Cry4Aa, Cry4Ba, Cry10Aa, Cry11Aa, Cyt1Aa, and Cyt2Ba by Bti. Alternatively, simultaneous production of multiple toxins may function simply to increase insecticidal activity, e.g., simultaneous production of Cry1Ca and Cry9Aa exerted a synergistic effect against $H$. armigera [89]. In addition, synergism between 3D-Cry and Cyt toxins and between 3D-Cry toxins and vegetative insecticidal protein has been reported $[90,91]$. The utility of this strategy used by B. thuringiensis is increasingly useful to Bt spray and 3D-Cry toxin gene-integrated GMOs.

Supplementary Materials: The following are available online at http:/ / www.mdpi.com/2072-6651/11/2/124/s1, Video S1 1. Swelling of BmABCC2-expressing Sf9 cells incubated with $1.2 \mu \mathrm{M}$ Cry1Aa. In the video, $32 \mathrm{~min}$ are shortened to $10 \mathrm{~s}$. Under phase-contrast microscopy, the cells started swelling after $3 \mathrm{~min}$, became non-refractive, reached the maximum volume after $15 \mathrm{~min}$, and burst.

Author Contributions: R.S. conceptualized, wrote and reviewed the manuscript. S.A., X.L., S.T. and H.E. gathered information and prepared the figures. S.A. and X.L. also conducted additional experiments for sharpening the vision.

Funding: This work was supported financially by a Grant-in-Aid for Scientific Research (B) (18H03397) from the Ministry of Education, Culture, Sports, Science, and Technology of Japan.

Conflicts of Interest: The authors declare no conflict of interest.

\section{Abbreviations}

$\begin{array}{ll}\text { ABC transporters } & \text { ATP-binding cassette transporters } \\ \text { 3D-Cry toxins } & \text { 3-domain Cry toxins } \\ \text { ABCC2 } & \text { ABC transporter family C2 } \\ \text { ABCB1 } & \text { ABC transporter family B1 } \\ \text { ABCA2 } & \text { ABC transporter family A2 } \\ \text { ECL } & \text { extracellular loop } \\ \text { BtR175-TBR } & \text { BtR175 toxin-binding region } \\ \text { SPR } & \text { surface plasmon resonance }\end{array}$

\section{References}

1. Fred, G.; Arne, A.; Alan, R.; Lara, B.; William, M. Selection and genetic analysis of a Heliothis virescens (Lepidoptera: Noctuidae) strain with high levels of resistance to Bacillus thuringiensis toxins. J. Econ. Entomol. 1995, 88, 1545-1559. [CrossRef]

2. Tabashnik, B.E.; Liu, Y.-B.; Finson, N.; Masson, L.; Heckel, D.G. One gene in diamondback moth confers resistance to four Bacillus thuringiensis toxins. Proc. Natl. Acad. Sci. USA 1997, 94, 1640-1644. [CrossRef] [PubMed]

3. Gahan, L.J.; Pauchet, Y.; Vogel, H.; Heckel, D.G. An ABC transporter mutation is correlated with insect resistance to Bacillus thuringiensis Cry1Ac toxin. PLoS Genet. 2010, 6, 1-11. [CrossRef] [PubMed] 
4. Crickmore, N.; Badenes-Pérez, F.R.; Baxter, S.W.; Heckel, D.G.; Jiggins, C.D.; Kain, W.; Morrison, A.; Vogel, H.; Wang, P.; Badenes-Pérez, F.R.; et al. Parallel evolution of Bt toxin resistance in lepidoptera. Genetics 2011, 189, 1-19. [CrossRef]

5. Xiao, Y.; Zhang, T.T.; Liu, C.; Heckel, D.G.; Li, X.; Tabashnik, B.E.; Wu, K. Mis-Splicing of the ABCC2 gene linked with Bt toxin resistance in Helicoverpa armigera. Sci. Rep. 2014, 4, 6184. [CrossRef]

6. Atsumi, S.; Miyamoto, K.; Yamamoto, K.; Narukawa, J.; Kawai, S.; Sezutsu, H.; Kobayashi, I.; Uchino, K.; Tamura, T.; Mita, K.; et al. Single amino acid mutation in an ATP-binding cassette transporter gene causes resistance to Bt toxin Cry1Ab in the silkworm, Bombyx mori. Proc. Natl. Acad. Sci. USA 2012, 109, E1591-E1598. [CrossRef] [PubMed]

7. Jurat-Fuentes, J.L.; Adang, M.J. Characterization of a Cry1Ac-receptor alkaline phosphatase in susceptible and resistant Heliothis virescens Larvae. Eur. J. Biochem. 2004, 271, 3127-3135. [CrossRef] [PubMed]

8. Wang, P.; Zhao, J.-Z.; Rodrigo-simo, A.; Kain, W.; Janmaat, A.F.; Shelton, A.M.; Ferre, J.; Myers, J. Mechanism of resistance to Bacillus thuringiensis toxin Cry1Ac in a greenhouse population of the cabbage looper, Trichoplusia ni. Appl. Environ. Microbiol. 2007, 73, 1199-1207. [CrossRef] [PubMed]

9. Nagamatsu, Y.; Koike, T.; Sasaki, K.; Yoshimoto, A.; Furukawa, Y. The cadherin-like protein is essential to specificity determination and cytotoxic action of the Bacillus thuringiensis insecticidal CryIAa toxin. FEBS Lett. 1999, 460, 385-390. [CrossRef]

10. Gahan, L.J.; Gould, F.; Heckel, D.G. Identification of a gene associated with Bt resistance in Heliothis Virescens. Science 2001, 293, 857-860. [CrossRef]

11. Xu, X.; Yu, L.; $\mathrm{Wu}, \mathrm{Y}$. Disruption of a cadherin gene associated with resistance to Cry1Ac $\delta$-endotoxin of Bacillus thuringiensis in Helicoverpa armigera. Appl. Environ. Microbiol. 2005, 71, 948-954. [CrossRef] [PubMed]

12. Morin, S.; Biggs, R.W.; Sisterson, M.S.; Shriver, L.; Ellers-Kirk, C.; Higginson, D.; Holley, D.; Gahan, L.J.; Heckel, D.G.; Carrière, Y.; et al. Three cadherin alleles associated with resistance to Bacillus thuringiensis in pink bollworm. Proc. Natl. Acad. Sci. USA 2003, 100, 5004-5009. [CrossRef] [PubMed]

13. Tabashnik, B.E.; Finson, N.; Groeters, F.R.; Moart, W.J.; Johnson, M.W.; Luo, K.; Adang, M.J. Reversal of resistance to Bacillus thuringiensis in Plutella xylostella. Proc. Natl. Acad. Sci. USA 1994, 91, 4120-4124. [CrossRef] [PubMed]

14. Mahon, A.R.J.; Olsen, K.M.; Garsia, K.A.; Young, S.R. Resistance to Bacillus thuringiensis toxin Cry2Ab in a strain of Helicoverpa armigera (Lepidoptera: Noctuidae) in Australia. J. Econ. Entomol. 2007, 100, 894-902. [CrossRef]

15. Tay, W.T.; Mahon, R.J.; Heckel, D.G.; Walsh, T.K.; Wslsh, T.K.; Downes, S.; James, W.J.; Lee, S.-F.; Reineke, A.; Williams, A.K.; et al. Insect resistance to Bacillus thuringiensis toxin Cry2Ab is conferred by mutations in an ABC transporter subfamily A protein. PLoS Genet. 2015, 11, 1-23. [CrossRef] [PubMed]

16. Wang, J.; Wang, H.; Liu, S.; Liu, L.; Tay, T.W.; Walsh, T.K.; Yang, Y.; Wu, Y. CRISPR/Cas9 mediated genome editing of helicoverpa armigera with mutations of an $\mathrm{ABC}$ transporter gene HaABCA2 confers resistance to Bacillus thuringiensis Cry2A toxins. Insect Biochem. Mol. Biol. 2017, 87, 147-153. [CrossRef] [PubMed]

17. Pauchet, Y.; Bretschneider, A.; Augustin, S.; Heckel, D.G. A P-glycoprotein is linked to resistance to the Bacillus thuringiensis Cry3Aa toxin in a leaf beetle. Toxins 2016, 8, 362. [CrossRef] [PubMed]

18. Aller, S.G.; Yu, J.; Ward, A.; Weng, Y.; Chittaboina, S.; Zhuo, R.; Harrell, P.M.; Trinh, Y.T.; Zhang, Q.; Urbatsch, I.L.; et al. Structure of P-glycoprotein reveals a molecular basis for poly-specific drug binding. Science 2009, 323, 1718-1722. [CrossRef] [PubMed]

19. Gazit, E.; La Rocca, P.; Sansom, M.S.; Shai, Y. The structure and organization within the membrane of the helices composing the pore-forming domain of Bacillus thuringiensis delta-endotoxin are consistent with an "umbrella-like" structure of the pore. Proc. Natl. Acad. Sci. USA 1998, 95, 12289-12294. [CrossRef]

20. Schwartz, J.-L.; Lu, Y.-J.; Söhnlein, P.; Brousseau, R.; Laprade, R.; Masson, L.; Adang, M.J. Ion channels formed in planar lipid bilayers by Bacillus thuringiensis toxins in the presence of Manduca sexta midgut receptors. FEBS Lett. 1997, 412, 270-276. [CrossRef]

21. Sangadala, S.; Walters, F.S.; English, L.H.; Adangt, M.J. A mixture of Manduca sexta aminopeptidase and phosphatase enhances Bacillus thuringiensis insecticidal CrylA(c) toxin binding and $86 \mathrm{Rb}(+)-\mathrm{K}+$ efflux in vitro. J. Biol. Chem. 1994, 269, 10088-10092.

22. Luo, K.; Sangadala, S.; Masson, L.; Mazza, A.; Brousseau, R.; Adang, M.J. The Heliothis virescens 170 KDa aminopeptidase functions as "receptor A" by mediating specific Bacillus thuringiensis Cry1A $\delta$-endotoxin binding and pore formation. Insect Biochem. Mol. Biol. 1997, 27, 735-743. [CrossRef] 
23. Heckel, D.G. Learning the ABCs of Bt: $\mathrm{ABC}$ transporters and insect resistance to Bacillus thuringiensis provide clues to a crucial step in toxin mode of action. Pestic. Biochem. Physiol. 2012, 104, 103-110. [CrossRef]

24. Tanaka, S.; Endo, H.; Adegawa, S.; Iizuka, A.; Imamura, K.; Kikuta, S.; Sato, R. Bombyx mori ABC transporter C2 structures responsible for the receptor function of Bacillus thuringiensis Cry1Aa toxin. Insect Biochem. Mol. Biol. 2017, 3, 1-11. [CrossRef]

25. Pardo-López, L.; Soberón, M.; Bravo, A. Bacillus thuringiensis insecticidal three-domain Cry toxins: Mode of action, insect resistance and consequences for crop protection. FEMS Microbiol. Rev. 2013, 37, 3-22. [CrossRef] [PubMed]

26. Endo, Y.; Nishiitsutsuji-Uwo, J. Mode of action of Bacillus thuringiensis $\delta$-endotoxin: Histopathological changes in the silkworm midgut. J. Insect Physiol. 1980, 36, 90-103. [CrossRef]

27. Tanaka, S.; Yoshizawa, Y.; Sato, R. Response of midgut epithelial cells to Cry1Aa is toxin-dependent and depends on the interplay between toxic action and the host apoptotic response. FEBS J. 2012, 279, 1071-1079. [CrossRef]

28. Zhang, X.; Candas, M.; Griko, N.B.; Rose-Young, L.; Bulla, L.A., Jr. Cytotoxicity of Bacillus thuringiensis $\mathrm{Cry} 1 \mathrm{Ab}$ toxin depends on specific binding of the toxin to the cadherin receptor BT-R1 expressed in insect cells. Cell Death Differ. 2005, 12, 1407-1416. [CrossRef]

29. Zhang, X.; Candas, M.; Griko, N.B.; Taussig, R.; Bulla, L.A., Jr. A mechanism of cell death involving an adenylyl cyclase/PKA signaling pathway is induced by the Cry1Ab toxin of Bacillus thuringiensis. Proc. Natl. Acad. Sci. USA 2006, 103, 9897-9902. [CrossRef]

30. Tanaka, S.; Miyamoto, K.; Noda, H.; Jurat-Fuentes, J.L.; Yoshizawa, Y.; Endo, H.; Sato, R. The ATP-binding cassette transporter subfamily $\mathrm{C}$ member 2 in Bombyx mori larvae is a functional receptor for cry toxins from Bacillus thuringiensis. FEBS J. 2013, 280, 1782-1794. [CrossRef]

31. Endo, H.; Tanaka, S.; Imamura, K.; Adegawa, S.; Kikuta, S.; Sato, R. Cry toxin specificities of insect ABCC transporters closely related to lepidopteran ABCC2 transporters. Peptides 2017, 98, 1-7. [CrossRef]

32. Obata, F.; Tanaka, S.; Kashio, S.; Tsujimura, H.; Sato, R.; Miura, M. Induction of Rapid and selective cell necrosis in Drosophila using Bacillus thuringiensis Cry toxin and its silkworm receptor. BMC Biol. 2015, 13, 48. [CrossRef] [PubMed]

33. Bretschneider, A.; Heckel, D.G.; Vogel, H. Know your ABCs: Characterization and gene expression dynamics of ABC transporters in the polyphagous herbivore Helicoverpa armigera. Insect Biochem. Mol. Biol. 2016, 72, 1-9. [CrossRef] [PubMed]

34. Stevens, T.; Song, S.; Bruning, J.B.; Choo, A.; Baxter, S.W. Expressing a moth Abcc2 Gene in transgenic Drosophila causes susceptibility to Bt Cry1Ac without requiring a cadherin-like protein receptor. Insect Biochem. Mol. Biol. 2017, 80, 61-70. [CrossRef]

35. Carroll, J.; Ellar, D.J. Analysis of the large aqueous pores produced by a Bacillus thuringiensis protein insecticide in manduca sexta midgut-brush-border-membrane vesicles. Eur. J. Biochem. 1997, 245, 797-804. [CrossRef] [PubMed]

36. Liebig, B.; Stetson, D.L.; Dean, D.H. Quantification of the effect of Bacillus thuringiensis toxins on short-circuit current in the midgut of Bombyx mori. J. Insect Physiol. 1995, 41, 17-22. [CrossRef]

37. Hubbard, T.J.P.; Murzin, A.G.; Brenner, S.E.; Chothia, C. SCOP: A structural classification of proteins database. Nucleic Acids Res. 1997, 25, 236-239. [CrossRef] [PubMed]

38. Ridleya, H.; Johnson, C.L.; Lakey, J.H. Interfacial interactions of pore-forming colicins. In Proteins Membrane Binding and Pore Formation; Anderluh, G., Lakey, J., Eds.; Springer: New York, NY, USA, 2010; pp. 81-90. [CrossRef]

39. London, E. The mechanism of diphtheria toxin translocation across membranes. In Membrane Protein Transport; Rothman, S.S., Ed.; Elsevier BV: Amsterdam, The Netherlands, 1995; Volume 1, pp. 201-227. [CrossRef]

40. Endo, H.; Azuma, M.; Adegawa, S.; Kikuta, S.; Sato, R. Water influx via aquaporin directly determines necrotic cell death induced by the Bacillus Thuringiensis Cry toxin. FEBS Lett. 2016, 591, 56-64. [CrossRef]

41. Knowles, B.H.; Ellar, D.J. Colloid-osmotic liysis is a general feature of the mechanism of action of Bacillus thuringiensis $\delta$-endotoxins with different insect specificity. BBA-Gen. Subj. 1987, 924, 509-518. [CrossRef]

42. Tanaka, S.; Endo, H.; Adegawa, S.; Kikuta, S.; Sato, R. Functional characterization of Bacillus thuringiensis Cry toxin receptors explains resistance in insects. FEBS J. 2016, 1-17. [CrossRef] 
43. Vadlamudi, R.K.; Ji, T.H.; Bulla, L.A. A specific binding protein from Manduca sexta for the insecticidal toxin of Bacillus thuringiensis Subsp. Berliner. J. Biol. Chem. 1993, 268, 12334-12340.

44. Yaoi, K.; Nakanishi, K.; Kadotani, T.; Imamura, M.; Koizumi, N.; Iwahana, H.; Sato, R. Bacillus thuringiensis Cry1Aa toxin-binding region of Bombyx mori aminopeptidase N. FEBS Lett. 1999, 463, 221-224. [CrossRef]

45. Mcnall, R.J.; Adang, M.J. Identification of novel Bacillus thuringiensis Cry1Ac binding proteins in Manduca sexta midgut through proteomic analysis. Insect Biochem. Mol. Biol. 2003, 33, 999-1010. [CrossRef]

46. Hossain, D.M.; Shitomi, Y.; Moriyama, K.; Higuchi, M.; Hayakawa, T.; Mitsui, T.; Sato, R.; Hori, H. Characterization of a novel plasma membrane protein, expressed in the midgut epithelia of Bombyx mori, that binds to Cry1A toxins. Appl. Environ. Microbiol. 2004, 70, 4604-4612. [CrossRef]

47. Pandian, G.N.; Ishikawa, T.; Vaijayanthi, T.; Hossain, D.M. Formation of macromolecule complex with Bacillus thuringiensis Cry1A Toxins and chlorophyllide binding 252-KDa lipocalin-like protein locating on Bombyx mori midgut membrane. J. Membr. Biol. 2010, 125-136. [CrossRef]

48. Valaitis, A.P.; Jenkins, J.L.; Lee, M.K.; Dean, D.H.; Garner, K.J. Isolation and partial characterization of gypsy moth BTR-270, an anionic brush border membrane glycoconjugate that binds Bacillus thuringiensis Cry1A toxins with high affinity. Collab. Entomol. Soc. Am. 2001, 46, 2001. [CrossRef]

49. Galián, C.; Manon, F.; Dezi, M.; Torres, C.; Ebel, C.; Lévy, D.; Jault, J.-M. Optimized purification of a heterodimeric $\mathrm{ABC}$ transporter in a highly stable form amenable to 2-D crystallization. PLoS ONE 2011, 6. [CrossRef]

50. Adegawa, S.; Nakama, Y.; Endo, H.; Shinkawa, N.; Kikuta, S.; Sato, R. The domain II loops of Bacillus thuringiensis Cry1Aa form an overlapping interaction site for two Bombyx mori larvae functional receptors, ABC transporter C2 and cadherin-like receptor. BBA Proteins Proteom. 2017, 1865, 220-231. [CrossRef]

51. Park, Y.; González-Martínez, R.M.; Navarro-Cerrillo, G.; Chakroun, M.; Kim, Y.; Ziarsolo, P.; Blanca, J.; Cañizares, J.; Ferré, J.; Herrero, S. ABCC transporters mediate insect resistance to multiple Bt toxins revealed by bulk segregant analysis. BMC Biol. 2014, 12, 46. [CrossRef]

52. Guo, Z.; Kang, S.; Zhu, X.; Xia, J.; Wu, Q.; Wang, S.; Xie, W.; Zhang, Y. The novel ABC transporter ABCH1 is a potential target for RNAi-based insect pest control and resistance management. Sci. Rep. 2015, 5, 13728. [CrossRef]

53. Chen, Z.; He, F.; Xiao, Y.; Liu, C.; Li, J.; Yang, Y.; Ai, H.; Peng, J.; Hong, H.; Liu, K. Endogenous expression of a Bt toxin receptor in the Cry1Ac-susceptible insect cell line and its synergistic effect with cadherin on cytotoxicity of activated Cry1Ac. Insect Biochem. Mol. Biol. 2015, 59, 1-17. [CrossRef]

54. Endo, H.; Tanaka, S.; Adegawa, S.; Ichino, F.; Tabunoki, H.; Kikuta, S.; Sato, R. Cro extracellular loop structures in silkworm ABCC transporters determine their specificities for Bacillus thuringiensis Cry. J. Biol. Chem. 2018, 293, 8569-8577. [CrossRef] [PubMed]

55. Xie, X.; Cheng, T.; Wang, G.; Duan, J.; Niu, W.; Xia, Q. Genome-wide analysis of the ATP-binding cassette (abc) transporter gene family in the silkworm, Bombyx mori. Mol. Biol. Rep. 2012, 39, 7281-7291. [CrossRef] [PubMed]

56. Augustin, S.; Courtin, C.; Rejasse, A.; Lorme, P.; Genissel, A.; Bourguet, D. Genetics of resistance to transgenic Bacillus thuringiensis poplars in Chrysomela tremulae (Coleoptera: Chrysomelidae). J. Econ. Entomol. 2004, 97, 1058-1064. [CrossRef]

57. Dermauw, W.; Van Leeuwen, T. The ABC gene family in arthropods: Comparative genomics and role ininsecticide transport and resistance. Insect Biochem. Mol. Biol. 2014, 45, 89-110. [CrossRef]

58. Tsuda, Y.; Nakatani, F.; Hashimoto, K.; Ikawa, S.; Matsuura, C.; Fukada, T.; Sugimoto, K.; Himeno, M. Cytotoxic activity of Bacillus thuringiensis Cry Proteins on mammalian cells transfected with cadherin-like Cry receptor gene of Bombyx mori (silkworm). Biochem. J. 2003, 369, 697-703. [CrossRef] [PubMed]

59. Hara, H.; Atsumi, S.; Yaoi, K.; Nakanishi, K.; Higurashi, S.; Miura, N.; Tabunoki, H.; Sato, R. A cadherin-like protein functions as a receptor for Bacillus thuringiensis Cry1Aa and Cry1Ac toxins on midgut epithelial cells of Bombyx Mori larvae. FEBS Lett. 2003, 538, 29-34. [CrossRef]

60. Banks, D.J.; Hua, G.; Adang, M.J. Cloning of a Heliothis Virescens 110 KDa aminopeptidase N and expression in drosophila S2 cells. Insect Biochem. Mol. Biol. 2003, 33, 499-508. [CrossRef]

61. Crava, C.M.; Bel, Y.; Jakubowska, A.K.; Ferré, J.; Escriche, B. Midgut aminopeptidase N isoforms from Ostrinia nubilalis: Activity characterization and differential binding to Cry1 $\mathrm{Ab}$ and Cry1Fa proteins from Bacillus thuringiensis. Insect Biochem. Mol. Biol. 2013, 43, 924-935. [CrossRef] 
62. Soberón, M.; Portugal, L.; Garcia-Gómez, B.-I.; Sánchez, J.; Onofre, J.; Gómez, I.; Pacheco, S.; Bravo, A. Cell lines as models for the study of Cry toxins from Bacillus thuringiensis. Insect Biochem. Mol. Biol. 2018, 93, 66-78. [CrossRef]

63. Chen, J.; Aimanova, K.G.; Pan, S.; Gill, S.S. Identification and characterization of Aedes aegypti aminopeptidase $\mathrm{N}$ as a putative receptor of Bacillus thuringiensis Cry11A toxin. Insect Biochem. Mol. Biol. 2009, 39, 688-696. [CrossRef]

64. Gill, M.; Ellar, D. Transgenic Drosophila reveals a functional in vivo receptor for the Bacillus thuringiensis toxin Cry1Ac1. Insect Mol. Biol. 2002, 11, 619-625. [CrossRef] [PubMed]

65. Kitami, M.; Kadotani, T.; Nakanishi, K.; Atsumi, S.; Higurashi, S.; Ishizaka, T.; Watanabe, A.; Sato, R. Bacillus Thuringiensis Cry toxins bound specifically to various proteins via domain III, which had a galactose-binding domain-like fold. Biosci. Biotechnol. Biochem. 2011, 7, 305-312. [CrossRef] [PubMed]

66. Pardo-López, L.; Gómez, I.; Rausell, C.; Sánchez, J.; Soberón, M.; Bravo, A. Structural changes of the Cry1Ac oligomeric pre-pore from Bacillus thuringiensis induced by $N$-Acetylgalactosamine facilitates toxin membrane insertion ${ }^{\dagger}$. Biochemistry 2006, 45, 10329-10336. [CrossRef]

67. Jurat-Fuentes, J.L.; Adang, M.J. The Heliothis virescens cadherin protein expressed in Drosophila S2 cells functions as a receptor for Bacillus thuringiensis Cry1A but not Cry1Fa toxins. Biochemistry 2006, 45, 9688-9695. [CrossRef]

68. Ren, X.-L.; Ma, Y.; Cui, J.-J.; Li, G.-Q. RNA interference-mediated knockdown of three putative aminopeptidases $\mathrm{N}$ affects susceptibility of Spodoptera exigua larvae to Bacillus thuringiensis Cry1Ca. J. Insect Physiol. 2014, 67, 28-36. [CrossRef]

69. Qiu, L.; Wang, P.; Zhang, B.; Liu, L.; Wang, X.; Lei, C.; Lin, Y.; Ma, W. Proteomic analysis of Cry1Ac and Cry2Aa binding proteins in brush border membrane vesicles of the Chilo suppressalis midgut. J. Asia. Pac. Entomol. 2017, 20, 1165-1169. [CrossRef]

70. Peña-Cardeña, A.; Grande, R.; Sánchez, J.; Tabashnik, B.E.; Bravo, A.; Soberón, M.; Gómez, I. The C-Terminal protoxin domain of Bacillus thuringiensis Cry1 Ab toxin has a functional role in binding to GPI-anchored receptors in the insect midgut. J. Biol. Chem. 2018, 2016, 1-21. [CrossRef]

71. Tanaka, S.; Miyamoto, K.; Noda, H.; Endo, H.; Kikuta, S.; Sato, R. Single amino acid insertions in extracellular loop 2 of Bombyx mori ABCC2 disrupt its receptor function for Bacillus thuringiensis Cry1Ab and Cry1Ac but not Cry1Aa toxins. Peptides 2016, 78, 99-108. [CrossRef]

72. Liu, L.; Chen, Z.; Yang, Y.; Xiao, Y.; Liu, C.; Ma, Y.; Soberón, M.; Bravo, A.; Yang, Y.; Liu, K. A single amino acid polymorphism in ABCC2 loop 1 is responsible for differential toxicity of Bacillus thuringiensis Cry1Ac toxin in different Spodoptera (Noctuidae) species. Insect Biochem. Mol. Biol. 2018, 100, 59-65. [CrossRef]

73. Gómez, I.; Sánchez, J.; Miranda, R.; Bravo, A.; Soberón, M. Cadherin-like receptor binding facilitates proteolytic cleavage of helix $\alpha-1$ in domain i and oligomer pre-pore formation of Bacillus thuringiensis Cry1Ab toxin. FEBS Lett. 2002, 513, 242-246. [CrossRef]

74. Gómez, I.; Dean, D.H.; Bravo, A.; Soberón, M. Molecular basis for Bacillus Thuringiensis Cry1Ab toxin specificity: Two structural determinants in the Manduca sexta Bt-R $\mathrm{R}_{1}$ receptor interact with loops $\alpha-8$ and 2 in domain II of Cy1Ab toxin ${ }^{\dagger}$. Biochemistry 2003, 42, 10482-10489. [CrossRef] [PubMed]

75. Xie, R.; Zhuang, M.; Ross, L.S.; Gomez, I.; Oltean, D.I.; Bravo, A.; Soberon, M.; Gill, S.S. Single amino acid mutations in the cadherin receptor from Heliothis virescens affect its toxin binding ability to Cry1A toxins. J. Biol. Chem. 2005, 280, 8416-8425. [CrossRef] [PubMed]

76. Wang, S.; Kain, W.; Wang, P. Bacillus thuringiensis Cry1A toxins exert toxicity by multiple pathways in insects. Insect Biochem. Mol. Biol. 2018, 102, 59-66. [CrossRef] [PubMed]

77. Ocelotl, J.; Sánchez, J.; Gómez, I.; Tabashnik, B.E.; Bravo, A.; Soberón, M. ABCC2 is associated with Bacillus thuringiensis Cry1Ac toxin oligomerization and membrane insertion in diamondback moth. Sci. Rep. 2017, 7, 2386. [CrossRef] [PubMed]

78. Endo, H.; Adegawa, S.; Kikuta, S.; Sato, R. The intracellular region of silkworm cadherin-like protein is not necessary to mediate the toxicity of Bacillus thuringiensis Cry1Aa and Cry1Ab toxins. Insect Biochem. Mol. Biol. 2018, 94, 36-41. [CrossRef]

79. Chen, J.; Hua, G.; Jurat-Fuentes, J.L.; Abdullah, M.A.; Adang, M.J. Synergism of Bacillus thuringiensis toxins by a fragment of a toxin-binding cadherin. Proc. Natl. Acad. Sci. USA 2007, 104, 13901-13906. [CrossRef] [PubMed] 
80. Park, Y.; Hua, G.; Abdullah, M.A.F.; Rahman, K.; Adang, M.J. Cadherin fragments from Anopheles gambiae synergize Bacillus thuringiensis Cry4Ba's toxicity against Aedes aegypti larvae. Appl. Environ. Microbiol. 2009, 75, 7280-7282. [CrossRef] [PubMed]

81. Hua, G.; Park, Y.; Adang, M.J. Cadherin AdCad1 in alphitobius diaperinus larvae is a receptor of $\mathrm{Cry} 3 \mathrm{Bb}$ toxin from Bacillus thuringiensis. Insect Biochem. Mol. Biol. 2014, 45, 11-17. [CrossRef] [PubMed]

82. Dorsch, J.A.; Candas, M.; Griko, N.B.; Maaty, W.S.A.; Midboe, E.G.; Vadlamudi, R.K.; Bulla, L.A., Jr. Cry1A toxins of Bacillus thuringiensis bind specifically to a region adjacent to the membrane-proximal extracellular domain of BT-R1in Manduca sexta: Involvement of a cadherin in the-entomopathogenicity of Bacillus thuringiensis. Insect Biochem. Mol. Biol. 2002, 32, 1025-1036. [CrossRef]

83. Bravo, A.; Sarabia, S.; Lopez, L.; Ontiveros, H.; Abarca, C.; Ortiz, A.; Ortiz, M.; Lina, L.; Villalobos, F.J.; Pen, G.; et al. Characterization of Cry genes in a Mexican Bacillus thuringiensis strain collection. Appl. Environ. Microbiol. 1998, 64, 4965-4972. [PubMed]

84. Martínez, C.; Caballero, P. Contents of cry genes and insecticidal toxicity of Bacillus thuringiensis strains from terrestrial and aquatic habitats. J. Appl. Entomol. 2002, 92, 745-752. [CrossRef]

85. Tabashnik, B.E.; Malvar, T.; Liu, Y.B.; Finson, N.; Borthakur, D.; Shin, B.S.; Park, S.H.; Masson, L.; de Maagd, R.A.; Bosch, D. Cross-resistance of the diamondback moth indicates altered interactions with domain II of Bacillus thuringiensis toxins. Appl. Environ. Microbiol. 1996, 62, 2839-2844. [CrossRef] [PubMed]

86. Zhao, J.-Z.; Li, Y.-X.; Collins, H.L.; Cao, J.; Earle, E.D.; Shelton, A.M. Different cross-resistance patterns in the diamondback moth (Lepidoptera: Plutellidae) resistant to Bacillus thuringiensis toxin Cry1C. J. Econ. Entomol. 2001, 94, 1547-1552. [CrossRef] [PubMed]

87. Paris, M.; Tetreau, G.; Laurent, F.; Lelu, M.; Despres, L.; David, J.-P. Persistence of Bacillus thuringiensis israelensis (Bti) in the environment induces resistance to multiple Bti toxins in mosquitoes. Pest Manag. Sci. 2011, 67, 122-128. [CrossRef]

88. Paul, A.; Harrington, L.H.; Zhang, L.; Scott, J.G. Insecticide resistance in Culex pipiens from New York. J. Am. Mosq. Control Assoc. 2005, 21, 2005.

89. Li, H.; Bouwer, G. Evaluation of the synergistic activities of Bacillus thuringiensis Cry proteins against Helicoverpa armigera (Lepidoptera: Noctuidae). J. Invertebr. Pathol. 2014, 121, 7-13. [CrossRef]

90. López-Diaz, J.A.; Cantón, P.E.; Gill, S.S.; Soberón, M.; Bravo, A. Oligomerization is a key step in Cyt1Aa membrane insertion and toxicity but not necessary to synergize Cry11Aa toxicity in Aedes aegypti larvae. Environ. Microbiol. 2013, 15, 3030-3039. [CrossRef] [PubMed]

91. Lemes, A.N.A.; Figueiredo, C.S.; Sebastião, I.; da Silva, L.M.; da Costa Alves, R.; de Siqueira, H.Á.A.; Franco Lemos, M.V.; Fernandes, O.A.; Desidério, J.A. Cry1Ac and Vip3Aa proteins from Bacillus thuringiensis targeting Cry toxin resistance in Diatraea flavipennella and Elasmopalpus lignosellus from sugarcane. Peer] 2017, 5, e2866. [CrossRef] [PubMed]

(c) 2019 by the authors. Licensee MDPI, Basel, Switzerland. This article is an open access article distributed under the terms and conditions of the Creative Commons Attribution (CC BY) license (http://creativecommons.org/licenses/by/4.0/). 